\title{
Reasons for Switching between Antipsychotics in Daily Clinical Practice
}

G. W. K. Hugenholtz ${ }^{1,2}$

E. R. Heerdink ${ }^{2}$

W. E. Meijer ${ }^{2}$

J.-J. Stolker ${ }^{1,2}$

A. C. G. Egberts ${ }^{1,2}$

W. A. Nolen ${ }^{1,3}$
Background: Previous research that atypical antipsychotics were switched less often compared to typical antpsychotics, suggesting overall better treatment satisfaction. The objective of this study was to investigate the reasons for switching antipsychotics after initiating oral treatment with either typical or atypical antipsychotics in a clinical setting. Patients and Methods: A total of 123 patients that switched antipsychotic therapy were recruited from 17 psychiatric hospitals, of which $46 \%$ switched because of lack of effect and $45 \%$ because of adverse effects. Results: No significant differences were found between users of atypical versus typical antipsychotics in reasons for switching, both for overall adverse events, and lack of effect. In users of atypical antipsychotics extrapyramidal effects were reported less often as reason for switching (adjusted OR $=0.18(95 \% \mathrm{CI}=(0.07-0.51))$. Patients on atypical antipsychotics switched more often because of weight gain (adjusted OR $=12.8(95 \% \mathrm{CI}=(1.50-109))$. Conclusion: In conclusion, when switching occurred, no difference was found in the frequency of general tolerability or reported lack of effectiveness. However, the type of adverse event as a reason for switching differed between atypical and typical antipsychotics.

\section{Introduction}

Antipsychotics are frequently used to manage acute symptoms and to prevent relapse in the treatment of patients with psychotic disorders [1]. The introduction of atypical antipsychotics has broadened the available treatment options. Switching from one antipsychotic to another may be seen as an overall expression of an unsatisfactory response to the initial treatment, including both treatment failure and the experience of adverse effects $[2,3]$.

In a previous retrospective follow-up study [4] of 522 newly admitted patients who started with an oral antipsychotic, we found that compared to typical oral antipsychotics, patients starting with an atypical oral antipsychotic had a lower incidence of switching to another antipsychotic (adjusted OR $=1.79 ; 95 \%$ $\mathrm{CI}=1.15-2.78)$. Moreover, the median time of switching was 24 days for patients on typical antipsychotics and 170 days for atypical antipsychotics. However, since this was a retrospective database study, we were unable to distinguish among switching because of a lack of effect, because of the occurrence of adverse effects, or because of other reasons.

The objective of the study presented here was to investigate the reasons for switching between antipsychotics - after initiating oral treatment with either typical or atypical antipsychotics - in a clinical setting and to study whether typical and atypical antipsychotics differ in that respect.

Affiliation

${ }^{1}$ Altrecht Institute for Mental Health Care, Utrecht, The Netherlands

2 Department of Pharmacoepidemiology and Pharmacotherapy, Utrecht Institute for Pharmaceutical Sciences (UIPS), Utrecht, The Netherlands

${ }^{3}$ Department of Psychiatry, University Hospital Groningen, Groningen and University Medical Center Utrecht, Utrecht, The Netherlands

Correspondence

Eibert R. Heerdink, PhD · Department of Pharmacoepidemiology and Pharmacotherapy · Utrecht Institute for Pharmaceutical Sciences (UIPS) · PO Box 80082 • 3508 TB Utrecht · The Netherlands · Phone: +31 302537324 . Fax: +31 $302539166 \cdot$-E-Mail: e.r.heerdink@pharm.uu.nl

Received 8.3.2004 $\cdot$ Revised $16.6 .2004 \cdot$ Accepted 18.10 .2004

Bibliography

Pharmacopsychiatry 2005; 38: 122-124 - Georg Thieme Verlag KG Stuttgart • New York

DOI $10.1055 / \mathrm{s}-2005-864122$

ISSN 0176-3679 


\section{Materials and Methods}

\section{Setting and study population}

We designed a prospective observational study to assess the reasons for switching from one antipsychotic to another in normal clinical practice. Hospital pharmacists in 17 psychiatric hospitals in the Netherlands agreed to each select up to 10 consecutive hospitalized patients, aged between 18 and 60 years, whose antipsychotic treatment had been altered by their physicians. Patients were included from June 2002 until February 2003. Prescribing physicians were asked to fill in a short questionnaire concerning the reasons for switching as well as clinical details of the patient.

\section{Data collection}

We defined a switch as any change in therapy from one oral antipsychotic to another oral antipsychotic. Clozapine, olanzapine, risperidone, sertindole, and quetiapine were classified as atypical antipsychotics. All other antipsychotics were classified as typical antipsychotics. Relevant clinical information was provided by the physician, including indication for prescribing an antipsychotic and psychiatric (co-)morbidity. Possible reasons for the switch were categorized into adverse effects, lack of effect, wish of the patient, or other reason. Furthermore, information on the duration of the initial antipsychotic treatment was gathered.

\section{Data analysis}

We compared the frequency of the types of switching in patients who were switched from atypical antipsychotics versus patients switched from typical antipsychotics and adjusted for possible confounding factors, including age, gender, and indication, using unconditional logistic regression. The strength of the associations was expressed as odds ratios with $95 \%$ confidence intervals (95\% CI).

\section{Results}

A total of 123 patients who switched oral antipsychotic treatment were recruited. Most patients (57.7\%) were younger than
40 years of age. Psychotic disorders accounted for $75.6 \%$ of the diagnoses of the patients. Other diagnoses included bipolar disorders $(7.3 \%)$, depressive disorders $(6.5 \%)$, and personality disorders (13.0\%). The initial (i.e., before switch) proportion of typical agents was $43.9 \%$, mostly consisting of zuclopenthixol $(18.7 \%$; median dose $=28 \mathrm{mg}$ ). The initial proportion of atypical antipsychotics was $56.1 \%$, mostly consisting of olanzapine $(26.0 \%$; median dose $=15 \mathrm{mg}$ ), risperidone $(18.7 \%$; median dose $=$ $4 \mathrm{mg}$ ), and quetiapine ( $9.8 \%$; median dose $=600 \mathrm{mg}$ ).

In Table $\mathbf{1}$ the reasons for switching are listed. The most important finding is that patients on atypical antipsychotics switched more often because of weight gain (adjusted OR $=12.8 ; 95 \%$ $\mathrm{CI}=1.50-109)$. Patients switching because of weight gain were initially treated with olanzapine (12 patients) or haloperidol (1 patient). No differences in reasons for switching were seen among diagnoses.

In an analysis on reasons for switching antipsychotic treatment in relation to time, we found that patients who switched within a week did so mostly because of adverse effects or other reasons, while only two patients (15.4\%) switched because of lack of effect. Patients who switched after at least two weeks did so mostly because of lack of effect.

\section{Discussion}

We found no differences in the frequency of tolerability or reported lack of effectiveness as reasons for switching from atypical versus typical antipsychotics. When focusing on specific adverse effects, however, we found that patients on atypical antipsychotics switched less often because of extrapyramidal side effects (EPS) and more often because of weight gain.

In our previous retrospective follow-up study [2], we found that patients initially treated with an atypical antipsychotic showed a better overall treatment satisfaction. However, in this study we had no information on reasons for switching. Combining the data found in both studies, we conclude that these patients

Table 1 Reported reason for switching antipsychotic treatment ${ }^{a}$

\begin{tabular}{|c|c|c|c|c|c|c|}
\hline \multirow[t]{2}{*}{ Reason } & \multicolumn{2}{|c|}{ Atypical } & \multicolumn{2}{|c|}{ Typical } & \multirow{2}{*}{$\begin{array}{l}\text { Crude } \\
\text { Odds ratioc } \\
(95 \% \mathrm{Cl})\end{array}$} & \multirow{2}{*}{$\begin{array}{l}\text { Adjusted }^{b} \\
\text { Odds ratio }^{c} \\
(95 \% \mathrm{Cl})\end{array}$} \\
\hline & $\begin{array}{l}\text { To typical } \\
\text { (n = 26) }\end{array}$ & $\begin{array}{l}\text { To atypical } \\
(\mathrm{n}=43)\end{array}$ & $\begin{array}{l}\text { To typical } \\
\text { (n=10) }\end{array}$ & $\begin{array}{l}\text { To atypical } \\
(\mathrm{n}=44)\end{array}$ & & \\
\hline Adverse effect & $7(26.9 \%)$ & $23(53.5 \%)$ & $1(10.0 \%)$ & $24(54.5 \%)$ & $0.89(0.44-1.83)$ & $0.60(0.23-1.62)$ \\
\hline EPS & $0(0.0 \%)$ & $11(25.6 \%)$ & $0(0.0 \%)$ & $20(45.5 \%)$ & $0.32(0.14-0.75)$ & $0.18(0.07-0.51)$ \\
\hline Sexual adverse effect & $0(0.0 \%)$ & $1(2.3 \%)$ & $0(0.0 \%)$ & $0(0.0 \%)$ & - & - \\
\hline Other adverse effect & $2(7.7 \%)$ & $6(14.0 \%)$ & $0(0.0 \%)$ & $6(13.6 \%)$ & $1.05(0.34-3.23)$ & $0.95(0.27-3.38)$ \\
\hline Lack of effect & $12(46.2 \%)$ & $21(48.8 \%)$ & $6(60.0 \%)$ & $18(40.9 \%)$ & $1.15(0.56-2.34)$ & $0.94(0.35-2.51)$ \\
\hline Wish of patient & $10(38.5 \%)$ & $6(14.0 \%)$ & $3(30.0 \%)$ & $11(25.0 \%)$ & $0.86(0.38-1.97)$ & $0.71(0.28-1.84)$ \\
\hline Compliance problem & $6(23.1 \%)$ & $0(0.0 \%)$ & $2(20.0 \%)$ & $3(6.8 \%)$ & $0.93(0.27-3.24)$ & $0.78(0.19-3.11)$ \\
\hline Other reasons & $0(0.0 \%)$ & $4(9.3 \%)$ & $1(10.0 \%)$ & $3(6.8 \%)$ & $0.77(0.18-3.23)$ & $0.38(0.07-2.14)$ \\
\hline
\end{tabular}

a Totals exceed $100 \%$ because of multiple reported reasons for switching.

${ }^{\mathrm{b}}$ Adjusted for age, gender, and indication for prescribing an antipsychotic.

' For the switch from atypical versus switch from typical. 
switched sooner because of adverse events. The majority of patients switched to atypical antipsychotics, from both a typical and an atypical antipsychotic.

Nearly all patients on atypical antipsychotics who switched because of EPS consisted of patients on risperidone. The patients starting with risperidone and switching because of EPS were on a median dose of $3.5 \mathrm{mg}$, ruling out high dosing as a plausible reason for the occurrence of EPS. Nearly all patients who switched because of weight gain were patients who used olanzapine.

Since we included only patients who switched their medication, one must be aware that the substances used more often have a higher chance of being switched and included in our cohort.

In conclusion, in patients switching antipsychotic treatment, no difference was found in the frequency of tolerability or reported lack of effectiveness. However, the type of side effect as a reason for switching differed between atypical and typical antipsychotics. We found that early switching of antipsychotic treatment was related to the occurrence of adverse effects, while switching after at least a few weeks was related to lack of effect.

\section{Acknowledgments}

The authors gratefully acknowledge the kind contribution of the participating clinical pharmacists and physicians.

\section{References}

${ }^{1}$ Davis JM, Janicak PG, Wang Z, Gibbons RD, Sharma RP. The efficacy of psychotropic drugs: implications for power analysis. Psychopharmacol Bull 1992; 28: 151 - 155

${ }^{2}$ Leslie DL, Rosenheck RA. From conventional to atypical antipsychotics and back: dynamic processes in the diffusion of new medications. Am J Psychiatry 2002; 159: $1534-1540$

${ }^{3}$ Weiden PJ, Aquila R, Dalheim L, Standard JM. Switching antipsychotic medications. J Clin Psychiatry 1997; 58: 63 - 72

${ }^{4}$ Hugenholtz GW, Heerdink ER, Nolen WA, Egberts AC. Less medication switching after initial start with atypical antipsychotics. Eur Neuropsychopharmacol 2004; 14: $1-5$ 